\title{
FONTES E NÍVEIS DE VITAMINA C PARA O CAMARÃO Litopenaeus vannamei NA FASE DE RECRIA
}

\author{
NeYVA Ribeiro FERRAZ ${ }^{1}$, RAFAEl VIEIRA AZEVEDO ${ }^{2}$, WANESSA QUEIROZ CAMBOIM ${ }^{3}$, MARCELO \\ CORDEIRO PEREIRA ${ }^{4}$, LuÍS GUSTAVO TAVARES BRAGA ${ }^{5}$ \\ ${ }^{1}$ Mestre pela Universidade Estadual de Santa Cruz, Ilhéus, BA, Brasil. \\ ${ }^{2}$ Doutorando da Universidade Estadual do Norte Fluminense, Campos de Goytacazes, RJ, Brasil. \\ ${ }^{3}$ Professora Mestre do Instituto Federal de Educação, Ciência e Tecnologia Baiano, Uruçuca, BA, Brasil. \\ ${ }^{4}$ Professor Mestre da Faculdade de Ilhéus, Ilhéus, BA, Brasil. \\ ${ }^{5}$ Professor Doutor da Universidade Estadual de Santa Cruz, Ilhéus, BA, Brasil. - lgtbraga@ gmail.com
}

\section{RESUMO}

Avaliou-se a inclusão de diferentes fontes e níveis de vitamina $\mathrm{C}$ no crescimento, sobrevivência, retenção de proteína e sanidade de Litopenaeus vannamei com peso inicial de 5,90 \pm 0,57 g. Quinhentos e quarenta exemplares foram distribuídos em 27 gaiolas em delineamento inteiramente casualizado, esquema fatorial $4 \times 2$ (quatro fontes e dois níveis), além do tratamento controle, isento de vitamina $\mathrm{C}(\mathrm{n}=3)$. As fontes utilizadas foram ácido ascórbico cristal, ácido ascórbico revestido, ácido ascórbico monofosfato e ácido ascórbico PEG (polietileno glicol) com dois níveis: 180 e $260 \mathrm{mg} \mathrm{kg}{ }^{-1}$. Não foi observada influência $(\mathrm{P}>0,05)$ da fonte, nível de vitamina $C$ nem interação desses fatores sobre $O$ crescimento, sobrevivência, retenção de proteína e parâmetros de sanidade dos camarões. Observou-se a presença de necrose no abdômen de todos os animais. A utilização de vitamina $\mathrm{C}$ nas fontes e níveis avaliados para o camarão Litopenaeus vannamei com peso acima de $5 \mathrm{~g}$ não revela melhorias no crescimento, sobrevivência, retenção de proteína e sanidade dos camarões.

PALAVRAS-CHAVE: Ácido ascórbico; carcinicultura; exigência nutricional; sanidade.

\section{VITAMIN C SOURCES AND LEVELS FOR SHRIMP Litopenaeus vannamei IN THE GROWING PHASE}

\section{ABSTRACT}

The inclusion of different sources and levels of vitamin $\mathrm{C}$ was evaluated on growth, survival, protein retention and health of Litopenaeus vannamei with initial weight of 5.90 $\pm 0.57 \mathrm{~g}$. Five hundred and forty individuals were distributed in 27 cages in a completely randomized design in a $4 \times 2$ factorial scheme (four sources and two levels) (n $=3$ ). The sources used were ascorbic acid crystal, coated ascorbic acid, ascorbic acid monophosphate and ascorbic acid PEG (polyethylene glycol) with two levels: 180 and
$260 \mathrm{mg} \mathrm{kg}-1$. No influence was observed $(\mathrm{P}>0.05)$ from the source, level of vitamin $\mathrm{C}$ nor interaction of these factors on growth, survival, retention of protein and parameters of health of the shrimp. Necrosis was observed in the abdomen of all animals. The use of vitamin $\mathrm{C}$ in sources and levels estimated for the shrimp Litopenaeus vannamei weighing over $5 \mathrm{~g}$ shows no improvement in growth, survival, protein retention and health of shrimp.

KEYWORDS: ascorbic acid; nutritional requirement; sanity; shrimp production.

\section{INTRODUÇÃO}

O Brasil teve o cultivo de crustáceos impulsionado pela produção do Litopenaeus vannamei, passando de 7.260 t em 1998 para 60.000 t em 2002. Seu desempenho (5.458 kg ha $\mathrm{ano}^{-1}$ ) o levou ao primeiro lugar em produtividade mundial (MENDES et al., 2006), sendo a região Nordeste responsável por cerca de $97 \%$ da produção nacional de camarões (CUNHA et al., 2006).

Entretanto, em 2004, o setor sofreu forte crise desencadeada, principalmente, pela disseminação do 
vírus da mancha branca em diversas fazendas de camarão, a ação antidumping dos Estados Unidos e a instabilidade do dólar (ARAÚJO et al., 2009). Em 2009, a carcinicultura representou $16 \%$ da aquicultura nacional com produção de 65.000 t (ROCHA, 2011).

Um dos nutrientes indispensáveis para a dieta de camarões são as vitaminas. A vitamina C desempenha papel importante na saúde animal como antioxidante, inativando radicais livres produzidos pela atividade celular normal e diversos agentes estressores (HALVER, 1995). Segundo HE \& LAWRENCE (1993) e NIU et al. (2009), o ácido ascórbico ou vitamina $\mathrm{C}$ é nutriente essencial para os camarões peneídeos, pois auxilia na manutenção e crescimento dos camarões, atua no organismo como co-fator para diversas reações bioquímicas (FUJIMOTO \& CARNEIRO, 2001; WANG et al., 2006), além de poder atuar como agente antioxidante, detoxificando numerosos peróxidos, oriundos do metabolismo (DARIAS et al., 2011), e agir como agente antiestressor e imunoestimulante (LEE \& SHIAU, 2002; MAGGIONI et al., 2004).

De acordo com ALMEIDA (2003), a suplementação dietética com vitamina $\mathrm{C}$ tem importância na eficiência alimentar, sanidade dos camarões e na economicidade das rações e da criação. Segundo MOREAU \& CUZON (1998) e LEE \& SHIAU (2002), a utilização de formas estáveis de ácido ascórbico é fator chave na determinação da exigência nutricional para o camarão. $\mathrm{O}$ problema da aplicação desse micronutriente para peneídeos é a falta de informações sobre doses ótimas na ração para esse organismo (HE \& LAWRENCE, 1993; LÓPEZ et al., 2003).

LÓPEZ et al. (2003) e MOE et al. (2005) afirmaram que rações com níveis inadequados de vitamina $\mathrm{C}$ na alimentação de camarões juvenis podem reduzir a taxa de crescimento, o apetite, a capacidade de restaurar tecidos lesionados, diminuir a resistência ao estresse e reduzir a frequência ou provocar mudas incompletas. CHEN \& CHANG (1994) e MERCHIE et al. (1997) acrescentam que rações com baixo nível de ácido ascórbico favorece o desenvolvimento de lesões negras (morte negra) em camarões.

Diante do exposto, objetivou-se avaliar diferentes fontes e níveis de vitamina $\mathrm{C}$ na ração para o camarão marinho Litopenaeus vannamei na fase de engorda, por meio de análises de desempenho produtivo, de retenção de nutrientes na carcaça e de sanidade.

\section{MATERIAL E MÉTODOS}

O experimento foi conduzido em propriedade particular, Fazenda Maricanes, localizada na Rodovia BA 001, km 18, situada no município de Canavieiras,
BA (1540’30'S e 38 56'50”W), durante 62 dias. Foi utilizado viveiro escavado, de $3.400 \mathrm{~m}^{2}$ de área e $1,2 \mathrm{~m}$ de profundidade média, com controle de abastecimento por bombeamento e drenagem de água por comportas.

Para a montagem do experimento, foram utilizadas 27 gaiolas confeccionadas com armação de vergalhões de aço (1 cm de diâmetro) e revestidas com malhas em PVC (malha de $6 \mathrm{~mm}$ ), com dimensões de 1 × 1 × $1 \mathrm{~m}$, as quais foram distribuídas no viveiro.

Foram utilizados 540 juvenis do camarão Litopenaeus vannamei, com peso inicial de 5,90 \pm 0,57 g, distribuídos aleatoriamente nas unidades experimentais de cultivo, a uma densidade de 20 indivíduos $\mathrm{m}^{-2}$, a mesma densidade utilizada na área de produção da fazenda. O delineamento experimental utilizado foi o inteiramente casualizado, em esquema fatorial 4 × 2 (quatro fontes e dois níveis de vitamina C), além do tratamento controle, isento de vitamina $\mathrm{C}$ $(n=3)$.

Confeccionou-se a ração controle (Tabela 1), isenta de vitamina $\mathrm{C}$, e a partir desta, nove rações experimentais foram formuladas, diferindo apenas quanto à fonte e o nível de vitamina $\mathrm{C}$. Foram avaliadas quatro fontes de vitamina $\mathrm{C}$ : ácido ascórbico cristal, ácido ascórbico revestido, ácido ascórbico monofosfato (sal cálcico 2-monofosfato de L-ácido ascórbico) e ácido ascórbico PEG (polietileno glicol) e dois níveis dessas fontes: 180 e $260 \mathrm{mg} \mathrm{kg}^{-1}$.

Tabela 1 - Composição percentual da ração controle para Litopenaeus vannamei

\begin{tabular}{lc}
\hline Ingrediente & $\begin{array}{c}\text { Ração base } \\
(\%)\end{array}$ \\
\hline Farinha de peixe 60\% & 15,00 \\
Glúten de milho 60\% & 9,35 \\
Farelo de soja 45\% & 25,96 \\
Farelo de trigo & 27,03 \\
Milho grão & 11,50 \\
Óleo de salmão & 3,63 \\
Suplemento (mineral e vitamínico) & 1,50 \\
Vitamina C & 0,00 \\
Celulose & 6,00 \\
Antioxidante BHT & 0,03
\end{tabular}

${ }^{\mathrm{T}}$ Níveis de garantia por kg: vit. A - $2200 \mathrm{UI}$; vit. E - 17,00 UI; vit. D3 - $1600 \mathrm{UI}$; vit. B6 -2,00 mg; vit. B1 - 2,50 mg; vit. B2 4,00 mg; vit. K - 2,5 mg; vit. B12 - 30,00 mcg; ac. fólico - 1,00 $\mathrm{mg}$; ac. pantotênico $-15,00 \mathrm{mg}$; biotina $-0,10 \mathrm{mg}$; colina $-4,50$ $\mathrm{mg}$; niacina $-50,00 \mathrm{mg}$; $\mathrm{Co}-0,03 \mathrm{mg} ; \mathrm{Cu}-7,50 \mathrm{mg} ; \mathrm{Fe}-50,00$ mg; I-2,00 mg; Mn - 50,00 mg; Se - 0,07 mg; Zn - 80,00 mg

As rações experimentais foram formuladas utilizando-se o software Super Crac® 4.0. Todos os ingredientes foram fornecidos pela empresa Agroceres Nutrição Animal, incluindo as fontes de 
vitamina C. As rações experimentais foram confeccionadas no Laboratório de Piscicultura da Universidade de São Paulo (USP), campus da Escola Superior de Agricultura Luiz de Queiroz (ESALQ).

Os ingredientes, com exceção do óleo de salmão e das misturas mineral e vitamínica, foram peneirados, pesados em balança de precisão $(0,01 \mathrm{~g})$ e posteriormente misturados em batedeira industrial. As fontes de vitamina $\mathrm{C}$ e as misturas mineral e vitamínica foram pesadas em balança de precisão $(0,001 \mathrm{~g})$ e adicionadas aos demais ingredientes. Em seguida, a mistura foi homogeneizada por mais cinco minutos, quando foi acrescentado o óleo de salmão.

Para a peletização das rações, acrescentou-se $800 \mathrm{~mL}$ de água e as misturas passaram por peletizadora com matriz de $4 \mathrm{~mm}$, sendo, em seguida, levadas para a estufa com circulação forçada de ar a $45^{\circ} \mathrm{C}$ por 24 horas. Depois de resfriadas à temperatura ambiente, as rações foram devidamente embaladas, identificadas e armazenadas em freezer $\left(-10^{\circ} \mathrm{C}\right)$ até o fornecimento aos camarões. As fontes de vitamina $\mathrm{C}$ foram incorporadas às rações experimentais no momento da mistura dos ingredientes.

No laboratório de Nutrição Animal da Universidade Estadual de Santa Cruz (UESC) foram feitas as análises bromatológicas de matéria seca, proteína bruta, extrato etéreo e cinzas, segundo SILVA \& QUEIROZ (2006). Para a determinação da energia bruta, foi utilizada bomba calorimétrica. As análises de fibra bruta, cálcio, fósforo e vitamina $\mathrm{C}$ foram realizadas pela empresa Agroceres Nutrição Animal (Tabela 2).

Tabela 2 - Composição analisada de nutrientes das rações experimentais para Litopenaeus vannamei

\begin{tabular}{lccccccccc}
\hline \multirow{2}{*}{ Item } & \multicolumn{10}{c}{ Ração $^{1}$} \\
\cline { 2 - 10 } & $\mathrm{C}$ & $\mathrm{F} 1$ & $\mathrm{~F} 1$ & $\mathrm{~F} 2$ & $\mathrm{~F} 2$ & $\mathrm{~F} 3$ & $\mathrm{~F} 3$ & $\mathrm{~F} 4$ & $\mathrm{~F} 4$ \\
& 0 & 180 & 260 & 180 & 260 & 180 & 260 & 180 & 260 \\
\hline Umidade (\%) & 7,70 & 6,90 & 6,10 & 6,60 & 4,60 & 6,40 & 5,80 & 6,70 & 6,00 \\
Proteína bruta (\%) & 35,56 & 34,98 & 36,17 & 35,96 & 36,21 & 36,29 & 36,53 & 35,84 & 36,01 \\
Energia bruta (kcal kg$\left.{ }^{-1}\right)$ & 4488 & 4528 & 4337 & 4511 & 4642 & 4619 & 4609 & 4536 & 4545 \\
Extrato etéreo (\%) & 5,51 & 6,83 & 5,94 & 6,23 & 6,36 & 5,93 & 5,90 & 6,19 & 6,24 \\
Fibra bruta (\%) & 4,49 & 6,56 & 4,78 & 5,29 & 5,63 & 4,29 & 6,65 & 4,04 & 5,77 \\
Cinza (\%) & 5,95 & 6,00 & 6,14 & 5,96 & 6,09 & 6,15 & 6,13 & 6,02 & 6,04 \\
Cálcio (\%) & 0,61 & 0,60 & 0,57 & 0,57 & 0,62 & 0,55 & 0,63 & 0,60 & 0,65 \\
Fósforo (\%) & 0,90 & 0,89 & 0,92 & 0,86 & 0,90 & 0,89 & 0,88 & 0,90 & 0,90 \\
Vitamina C (mg kg & 0,00 & 186 & 268 & 177 & 239 & 175 & 289 & 179 & 240 \\
\hline
\end{tabular}

${ }^{1} \mathrm{C}$, Ração controle (sem vitamina C); F1, Ácido ascórbico cristal (vit. C - 6\%); F2, Ácido ascórbico revestido (vit. C - 97\%); F3, Ácido ascórbico monofosfato (sal cálcico 2 - monofosfato de L-ácido ascórbico (vit. C - 35\%); F4, Ácido ascórbico PEG (polietileno glicol) (vit. C - 50\%).

As rações foram fornecidas aos camarões em bandejas, duas vezes ao dia, às $9 \mathrm{~h}$ e às $14 \mathrm{~h}$. Os parâmetros físico-químicos da água foram monitorados diariamente, utilizando-se equipamentos digitais portáteis, obtendo-se os seguintes resultados: $5,4 \pm 1,0$ para oxigênio dissolvido $\left(\mathrm{mg} \mathrm{L}^{-1}\right) ; 29,5 \pm 1,6$ para temperatura $\left({ }^{\circ} \mathrm{C}\right) ; 21,7 \pm 3,1$ para salinidade $(\mathrm{ppm})$ e $8,04 \pm 0,1$ para $\mathrm{pH}$, sendo que os resultados permaneceram dentro da faixa recomendada para a espécie (LOWEMCCONNEL, 1975; NEILL \& BRYAN, 1991; BOYD, 2001; NUNES \& MARTINS, 2002; KUBITZA, 2003).

No início do experimento, todos os animais de cada repetição foram pesados. Além disso, 20 animais foram coletados e sacrificados para realização de análises de composição corporal.
Ao final do período experimental, todos os animais foram pesados e sacrificados com superdosagem do anestésico Benzocaína $120 \mathrm{mg} \mathrm{L}^{-1}$ para determinação de parâmetros de desempenho e de retenção de nutrientes. As seguintes variáveis foram determinadas para a avaliação das diferentes rações: consumo de ração, ganho de peso [(biomassa final - biomassa inicial) / número de animais], conversão alimentar aparente [consumo de ração / ganho de peso], taxa de crescimento específico [Ln (peso final) - Ln (peso inicial) / período experimental x 100], taxa de sobrevivência [(número de animais mortos / número total de animais) x 100], taxa de eficiência proteica [ganho de peso / proteína consumida] e coeficiente de retenção da proteína bruta $[100 \mathrm{x}$ (proteína corporal final x peso final) (proteína corporal inicial x peso inicial) / proteína 
consumida $\mathrm{x}$ 100].

Para avaliar a sanidade dos animais, foram feitas observações quanto à conformação corporal e identificação de possíveis sintomas patológicos (ausência/presença de necrose). Ao final do experimento, todos os animais dos diferentes tratamentos passaram por análise macroscópica.

Os dados foram submetidos à análise de variância (ANOVA) com dois fatores, utilizando-se o software SAS 9.0 (SAS Inc., Cary, NC, USA).

\section{RESULTADOS E DISCUSSÃO}

Por meio da análise de variância bifatorial não foi observado efeito $(\mathrm{P}>0,05)$ da interação entre fonte e nível de vitamina $C$ utilizado na ração, sobre os índices de crescimento, sobrevivência, retenção de proteína bruta e parâmetros de sanidade nos camarões (Tabela 3).

Tabela 3 - Crescimento, sobrevivência e retenção de proteína bruta do Litopenaeus vannamei de acordo com a fonte e o nível de inclusão de vitamina $\mathrm{C}$ na ração ${ }^{1}$

\begin{tabular}{lccccccc}
\hline \multirow{2}{*}{ Tratamento } & \multicolumn{7}{c}{ Variável $^{2}$} \\
\cline { 2 - 8 } & CR & GP & CAA & TCE & TS & TEP & CRP \\
\hline Ácido ascórbico cristal & 9,53 & 6,86 & 1,41 & 1,28 & 81,44 & 2,02 & 91,58 \\
Ácido ascórbico revestido & 9,52 & 6,46 & 1,50 & 1,18 & 79,56 & 1,89 & 85,65 \\
Ácido ascórbico monofosfato & 9,50 & 6,80 & 1,42 & 1,24 & 81,89 & 1,98 & 91,92 \\
Ácido ascórbico PEG & 9,40 & 6,84 & 1,40 & 1,26 & 82,00 & 2,04 & 93,54 \\
$0 \mathrm{mg} \mathrm{kg}^{-1}$ & 9,49 & 6,63 & 1,47 & 1,23 & 79,00 & 1,96 & 88,22 \\
$180 \mathrm{mg} \mathrm{kg}^{-1}$ & 9,48 & 6,74 & 1,42 & 1,26 & 82,33 & 1,99 & 90,58 \\
$260 \mathrm{mg} \mathrm{kg}^{-1}$ & 9,49 & 6,85 & 1,40 & 1,23 & 82,33 & 1,99 & 93,22 \\
\hline $\mathrm{CV}(\%)$ & 2,65 & 15,72 & 14,99 & 15,27 & 7,76 & 15,38 & 15,44 \\
\hline Valor de P & & & & & & & \\
\hline Fonte & 0,6592 & 0,8793 & 0,7524 & 0,6687 & 0,8300 & 0,7410 & 0,6542 \\
Nível & 0,9873 & 0,8375 & 0,7011 & 0,9303 & 0,3428 & 0,9543 & 0,6854 \\
Fonte x Nível & 0,3294 & 0,9470 & 0,8734 & 0,8961 & 0,9946 & 0,9084 & 0,7567 \\
\hline
\end{tabular}

${ }^{1}$ Não houve diferença significativa ao nível de $5 \%$ de probabilidade pelo teste de Tukey.

${ }^{2} \mathrm{CR}$, consumo de ração; GP, ganho de peso; CAA, conversão alimentar aparente; TEC, taxa de crescimento específico; TS, taxa de sobrevivência; TEP, taxa de eficiência proteica; CRP, coeficiente de retenção da proteína bruta; CV, coeficiente de variação.

Não foi observada influência $(\mathrm{P}>0,05)$ da fonte de vitamina $\mathrm{C}$ utilizada na ração, ou seja, o crescimento, sobrevivência, retenção de proteína bruta e parâmetros de sanidade dos camarões alimentados com rações contendo ácido ascórbico nas formas cristal, revestido, monofosfato e PEG se equivalem. Do mesmo modo, o nível de inclusão da vitamina $C$ na ração não alterou $(\mathrm{P}>0,05)$ o crescimento, sobrevivência, retenção de proteína bruta e parâmetros de sanidade nos camarões.

Os resultados médios para consumo de ração, ganho de peso, conversão alimentar aparente e taxa de crescimento específico foram, respectivamente, 9,48 g, 6,78 g, 1,42:1 e 1,24\%. Esses resultados são semelhantes aos obtidos por outros autores (BARBIERI JR. \& OSTRENSKY NETO, 2002; MARTINEZ-CORDOVA et al., 2002; GOMEZ-JIMENEZ et al., 2005) que utilizaram camarões alimentados com rações com o mesmo nível de proteína bruta utilizado neste experimento

Esses resultados contrastam com os obtidos por LEE \& SHIAU (2002) que, trabalhando com diferentes fontes e níveis de vitamina $\mathrm{C}$ na ração para juvenis de Penaeus monodon $(0,37 \mathrm{~g})$, observaram que os camarões alimentados com qualquer uma das fontes e níveis obtiveram desempenho significativamente superior aos camarões alimentados com rações isentas de vitamina $\mathrm{C}$.

O valor médio observado para taxa de sobrevivência foi de $81,96 \%$. Esse valor é semelhante aos obtidos por SHIAU \& HSUB (1994) e por GOMEZ-JIMENEZ et al. (2005). Discordando desses resultados, HE \& LAWRENCE (1993), avaliando diferentes níveis de vitamina C (Lascorbil-polifosfato) em rações para $L$. vannamei $(0,1 \mathrm{~g})$, observaram que a sobrevivência dos animais alimentados com rações isentas de vitamina $\mathrm{C}$ foi significativamente inferior àqueles alimentados com inclusão de vitamina $C$.

As diferenças observadas tanto para os parâmetros de crescimento quanto para os de sobrevivência podem estar relacionadas às respectivas fases de desenvolvimento do camarão. 
Segundo HE \& LAWRENCE (1993) e NIU et al. (2009), a exigência de vitamina $C$ na ração de camarões decresce à medida que esses organismos crescem. Ainda segundo esses autores, o animal na fase inicial de crescimento tem maior porcentagem de mudança no peso por unidade de tempo, com isso, exige-se mais vitamina $\mathrm{C}$ para satisfazer suas necessidades metabólicas.

A taxa de eficiência proteica e o coeficiente de retenção da proteína bruta foram, em média, 2 e $91,5 \%$, respectivamente. A similaridade entre os resultados era esperada, uma vez que as rações experimentais eram isoproteicas e isoenergéticas e os camarões apresentaram desempenho semelhante.

Macroscopicamente, não foram observadas deformações no corpo dos camarões nos diversos tratamentos, porém a presença de necrose na carapaça dos animais (cefalotórax e abdômen) foi observada em todos os tratamentos (Figuras 1 e 2).

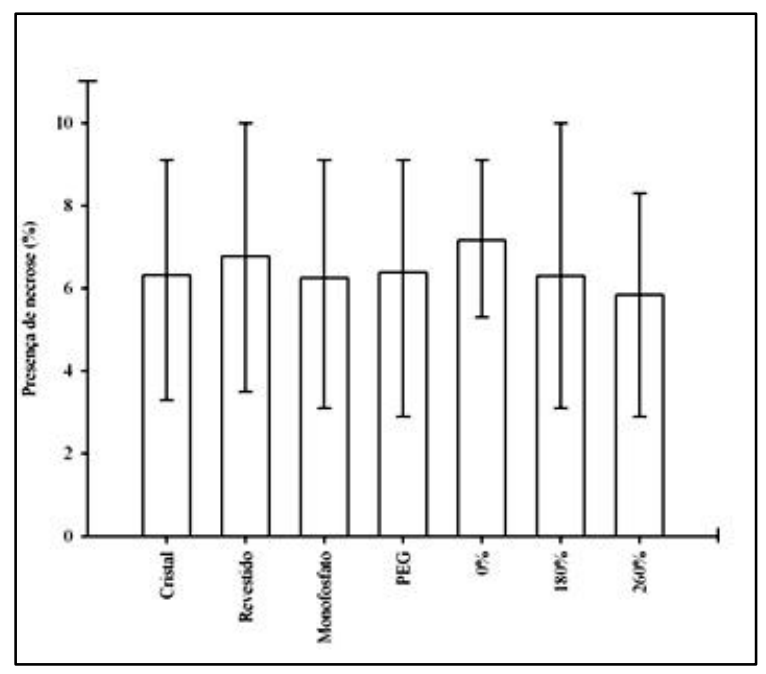

Figura 1 - Presença de necrose (média \pm desvio padrão) em Litopenaeus vannamei de acordo com a fonte e o nível de vitamina C.

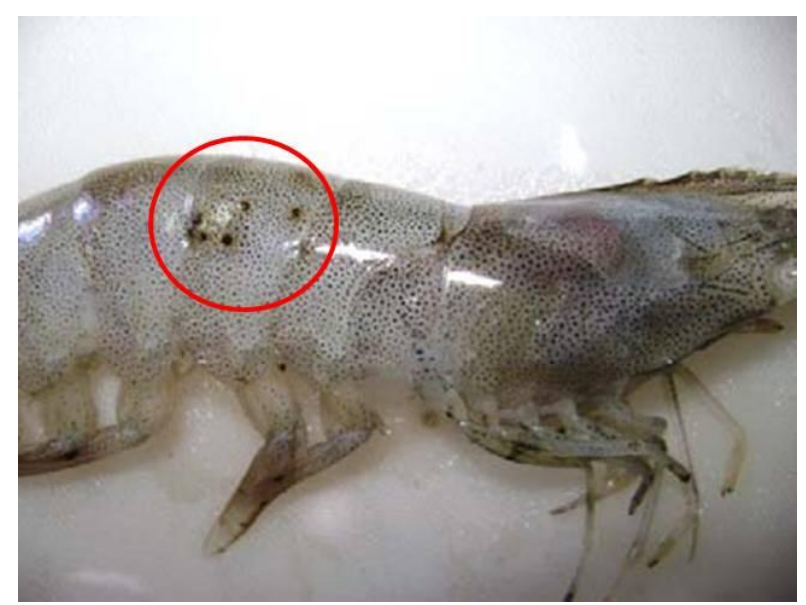

Figura 2 - Pontos de necrose no abdômen do Litopenaeus vannamei.
Além de crescimento reduzido, a deficiência de vitamina $\mathrm{C}$ pode ser responsável por anormalidades físicas e deformidades do esqueleto em camarões (DESHIMARU \& KUROKI, 1976; SHIGUENO \& ITOH, 1988; HE \& LAWRENCE, 1993), as quais não foram observadas em nenhum exemplar, independentemente do tratamento. No entanto, a presença de necrose, que é resultado da reação enzimática em decorrência de situação de estresse (ABCC, 2005), foi observada em todos os exemplares, o que pode estar relacionado à restrição a movimentação dos camarões quando mantidos em gaiolas de $1 \mathrm{~m}^{3}$. Isso sugere que a maior concentração de vitamina C utilizada não foi suficiente para aliviar esse fator estressante.

De acordo com NRC (2011), a exigência de vitamina C pelo L. vannamei varia de 90 a 190 $\mathrm{mg} / \mathrm{kg}$ da dieta. Mesmo para os animais alimentados com rações isentas de vitamina $C$, a exigência desse nutriente pode ter sido atendida pelo consumo, ainda que restrito, do alimento natural presente no viveiro de cultivo.

Como não houve efeito das diferentes fontes e níveis de vitamina $\mathrm{C}$ sobre o crescimento, a sobrevivência e a sanidade dos camarões em todos os tratamentos, sugere-se que a inclusão de vitamina $\mathrm{C}$ em concentrações acima do avaliado pode reduzir ou eliminar o possível estresse nos camarões acima de 5 g causado pela restrição de espaço

\section{CONCLUSÕES}

A utilização de vitamina $\mathrm{C}$ até o nível de 260 $\mathrm{mg} /$ não revela melhorias no desempenho e a sanidade do camarão Litopenaeus vannamei na fase de recria.

\section{AGRADECIMENTOS}

À empresa Agroceres Nutrição Animal pela doação dos ingredientes para confecção das rações experimentais. Ao professor José Eurico Possebon Cyrino que viabilizou a fabricação das rações. À Associação de Carcinicultores de Canavieiras-BA pelo auxílio financeiro e aos proprietários da fazenda Maricanes por permitirem a realização da pesquisa em sua propriedade.

\section{REFERÊNCIAS}

ABCC. Associação Brasileira de Criadores de Camarão. Programa de biossegurança para fazendas de camarão marinho. 1. ed. Recife, 2005. p.68.

ALMEIDA, G. S. C. Suplementação dietética de 
vitamina C, desenvolvimento e sanidade do pacu (Piaractus mesopotamicus Holmberg, 1887). 2003. 65 f. Dissertação (Mestrado Ciência Animal e Pastagens) Escola Superior de Agricultura Luiz de Queiroz, Universidade de São Paulo, São Paulo, SP. Disponível em:

http://www.teses.usp.br/teses/disponiveis/11/11139/tde09022004-155038/pt-br.php, acesso em julho de 2012.

ARAÚJO, D. M. A.; OKINO, F.; YUMI, M. Qualidade dos empregos da carcinicultura na praia de Barreta/RN. Organizações Rurais e Agroindustriais, v. 11, n. 01, p. $140-156,2009$

BARBIERI JÚNIOR, R. C.; OSTRENSKY NETO, A Camarões marinhos - Engorda. v.2. Viçosa: Aprenda Fácil Press, 2002. p.370.

BOYD, C. E. Inland shrimp farming and the environment. World Aquaculture, v. 32, n. 1, p. 10-12, 2001.

DARIAS, $\quad$ M. $\quad$ J.; MAZURAIS, D.; KOUMOUNDOUROS, G.; CAHU, C. L.; ZAMBONINO-INFANTE, J. L. Overview of vitamin D and $\mathrm{C}$ requirements in fish and their influence on the skeletal system. Aquaculture, v. 315, n. 1-2, 1, p. 49-60, 2011.

CHEN, H. Y.; CHANG. C. F. Quantification of vitamin C requirement for juvenile shrimp (Penaeus monodon) using polyphosphorylated L-ascorbic acid. Journal of Nutrition, v. 124, n. 01, p. 2033-2038, 1994.

CUNHA, F. S. A.; RABELLO, C. B.; DUTRA JUNIOR, W. M.; LUDKE, M. C. M. M.; LOUREIRO, R. R. S.; FREITAS, C. R. G. Desempenho e características de carcaça de frangos de corte alimentados com dietas contendo farinha de resíduos do processamento de camarões (Litopeneaus vannamei). Acta Scientiarum. Animal Sciences, v. 28, n.3, p. 273-279, 2006.

DESHIMARU, O.; KUROKI, K. Adequate dietary levels of ascorbic acid for praw. Bulletin of the Japanese Society of Scientific Fisheries, v. 42, n.1, p. 571-576, 1976.

FUJIMOTO, R. Y.; CARNEIRO, D. J. Adição de ascorbil polifosfato, como fonte de vitamina $\mathrm{C}$ em dietas para alevinos de pintado, Pseudoplatystoma corruscans (Agassiz, 1829). Acta Scientiarum. Animal Sciences, v. 23, n.1, p. 855-861, 2001.

GOMEZ-JIMENEZ，S.; GONZALEZ- FELIX, M. L.; PEREZ-VELAZQUEZ, M.; TRUJILLO- VILLALBA, D. A.; ESQUERR- BRAUER, I. R.; BARRAZAGUARDADO, R. Effect of dietary protein level on growth, survival and ammonia efflux rate of Litopenaeus vannamei (Boone) raised in a zero water exchange culture system. Aquaculture Research, v. 36, p. 834-840, 2005.

HALVER, J. E. Vitamin requirement study techniques. Journal of Applied Ichthyology, v. 11, p. 215-224, 1995.

HE, H.; LAWRENCE, A. L. Vitamin C requeriments of the shrimp Penaeus vannamei. Aquaculture, v. 114, n. 04, p. 305-316, 1993.
KUBITZA, F. Qualidade da Água no Cultivo de Peixes e Camarões. Acqua Supre Com. Suprim. Aquicultura Ltda.,Jaboticabal, SP. 1. ed. 2003. p.229.

LEE, M. H.; SHIAU, S. Y. Dietary vitamin C and its derivatives affect immune responses in grass shrimp, Penaeus monodon. Fish \& Shellfish Immunology, v. 12, n.2, p. 119-129, 2002.

LÓPEZ, N.; CUZON, G.; GAXIOLA, G.; TABOADA, G.; VALENZUELA, M.; PASCUAL, C.; SÁNCHEZ, A.; ROSAS, C. Physiological, nutritional, and immunological role of dietary 1-3 glucan and ascorbic acid 2monophosphate in Litopenaeus vannamei juveniles. Aquaculture, v. 224, p. 223-243, 2003.

LOWE-MCCONNEL, R. H. Fish communities in tropical freshwaters: their distribution, ecology and evolution. New York: Logman, Inc. 1975. p.123.

MAGGIONI, D. S.; ANDREATTA, E. R.; HERMES, E. M.; BARRACCO, M. A. Evaluation of some hematoimmunological parameters in female shrimp Litopenaeus vannamei submitted to unilateral eyestalk ablation in association with a diet supplemented with superdoses of ascorbic acid as a form of immunostimulation. Aquaculture, v. 241, p. 501-515, 2004

MARTINEZ-CORDOVA, L. R.; CAMPAÑA-TORRES, A.; PORCHAS-CORNEJO, M. A. The effects of variation in feed protein level on the culture of shrimp, Litopenaeus vannamei (Boone) in low-water exchange experimental ponds. Aquaculture Research, v. 33, n. 12, p. 995-998, 2002 .

MENDES, P. P.; ALBUQUERQUE, M. L. L. T.; QUEIROZ, D. M.; SANTOS, B. L. S.; LIMA, A. C.; LOPES, Y. V. A. Aclimatação do camarão marinho Litopenaeus vannamei (Boone, 1931) à água doce com diferentes estratégias de alimentação e calagem. Acta Scientiarum. Animal Sciences, v. 28, n.1, p. 89-95, 2006.

MERCHIE, G.; LAVENS, P.; SORGELOOS, P. Optimization of dietary vitamin $\mathrm{C}$ in fish and crustacean larvae: a review. Aquaculture, v. 155, n.1-2, p. 165-181, 1997.

MOE, Y. Y.; KOSHIO, S.; ISHIKAWA, M.; TESHIMA, S.; PANGANIBAN JR. A.; THU, M.; MICHAE, F. R.; REN, T. Vitamin C requirement of kuruma shrimp postlarvae, Marsupenaeus japonicus (Bate), using Lascorbyl-2- monophosphate- $\mathrm{Na} / \mathrm{Ca}$. Aquaculture Research, v. 36, p. 739-745, 2005.

MOREAU, R.; CUZON, G. Efficacy of silicone-coated ascorbic acid and ascorbyl-2-polyphosphate to fastgrowing tiger shrimp (Penaeus monodon). Aquaculture Nutrition, v. 04, n. 01, p. 23-29, 1998.

NATIONAL RESEARCH COUNCIL - NRC. Nutrient requeriments of fish and Shrimp. Washington, D.C.: National Research Council of the National Academies, 2011. 376p.

NEILL, W. H.; BRYAN, J. D. Responses of fish to 
temperature and oxygen, and response integration through metabolic scope. In: BRUNE, D. E.; TOMASSO, J. R. (Ed.). Aquaculture and water quality. Advances in world aquaculture. Baton Rouge: The World Aquaculture Society, 1991. p.30-57.

NIU, J.; TIAN, L. X.; LIU, Y. J. Nutrient Values of dietary ascorbic acid (L-ascorbyl- polyphosphate) on growth, survival and stress tolerance of larval shrimp, Litopenaeus vannamei. Aquaculture Nutrition, v.1, n.2, p. 194-201, 2009.

NUNES, A. J. P.; MARTINS, P. C. Assessing the health of marine shrimp fattening. Panorama da Aquicultura, v. 12, n. 72, p. 23-33, 2002.

ROCHA, I. P. Carcinicultura brasileira: Processos tecnológicos, impactos sócio-econômicos, sustentabilidade ambiental, entraves e oportunidades. Revista da ABCC, v. 13, n.1, p. 13-23, 2011.
SHIAU, S. Y.; HSUB, T. S. Vitamin C requirement of grass shrimp, Penaeus monodon, as determined with Lascorbyl-2-monophosphate. Aquaculture, v. 122, n.4, p. 347-357, 1994.

SHIGUENO, K.; ITOH, S. Use of Mg-L-ascorbyl-2phosphate as a vitamin $\mathrm{C}$ source in shrimp diets. Journal of the World Aquaculture, v. 19, n.4, p. 168-174, 1988.

SILVA, D. J.; QUEIROZ, A. C. Análise de alimentos: métodos químicos e biológicos. 3. ed. Viçosa: UFV, 2006. p.235.

WANG, W. N.; WANG, Y.; WANG, A. L. Effect of supplemental L-ascorbyl-2-polyphosphate (APP) in enriched live food on the immune response of Penaeus vannamei exposed to ammonia-N. Aquaculture, v. 256, n.1-4, p. 552-557, 2006.

Protocolado em: 25 jun. 2011. Aceito em: 10 ago. 2012. 